\title{
Challenges in the development of prognostic models utilising clinical trials data
}

\author{
Kym Snell ${ }^{1 *}$, Lucinda Billingham ${ }^{1,2}$, Deborah Stocken ${ }^{3}$, Richard Riley ${ }^{1}$ \\ From 2nd Clinical Trials Methodology Conference: Methodology Matters \\ Edinburgh, UK. 18-19 November 2013
}

\begin{abstract}
Aims
Prognostic models are statistical models that predict the risk of a future clinical outcome for individuals, and they are increasingly being developed using existing data from clinical trials. In this presentation we consider the challenges of this approach.
\end{abstract}

\section{Methods}

Using data from two clinical trials in advanced stage pancreatic cancer, a prognostic model was developed using Royston-Parmar (R-P) flexible parametric survival models. R-P models use restricted cubic splines to model the baseline hazard function for time-to-event data and thereby allows absolute risk to be predicted for individuals. This contrasts the Cox regression approach which does not explicitly model the baseline hazard function.

\section{Results}

We identified 6 key issues when using the trials' data to develop the prognostic model. These included dealing with multiple trials, handling multiple treatment groups with potentially different baseline hazard functions, and suitably using the data for model validation.

Informed judgement is needed to tackle these issues, and the baseline hazard function is pivotal to this. R-P models allow the baseline hazard to be displayed for all trials and all treatment groups. This aids decisions about whether to combine trials and treatment groups in the model development, and enables internal validation of predicted survival probabilities compared to observed probabilities from Kaplan-Meier plots.

'MRC Midland Hub for Trials Methodology Research, University of Birmingham, Birmingham, UK

Full list of author information is available at the end of the article

\section{Conclusion}

Clinical trials data is a rich source of existing data for prognostic model development, but it also provides many challenges. By modelling the baseline hazard, researchers can gain insight into how to tackle these issues.

\section{Authors' details}

'MRC Midland Hub for Trials Methodology Research, University of Birmingham, Birmingham, UK. ${ }^{2}$ Cancer Research UK Clinical Trials Unit, University of Birmingham, Birmingham, UK. ${ }^{3}$ Newcastle Clinical Trials Unit, Institute of Health and Society, Newcastle University, Newcastle, UK.

Published: 29 November 2013

doi:10.1186/1745-6215-14-S1-P115

Cite this article as: Snell et al:: Challenges in the development of prognostic models utilising clinical trials data. Trials 2013 14(Suppl 1): P115.
Submit your next manuscript to BioMed Central and take full advantage of:

- Convenient online submission

- Thorough peer review

- No space constraints or color figure charges

- Immediate publication on acceptance

- Inclusion in PubMed, CAS, Scopus and Google Scholar

- Research which is freely available for redistribution
C Biomed Central

\section{Biomed Central}

